ESCRITAS Vol. 11 n. 1 (2019) ISSN 2238-7188 p.52-66

\title{
GEOTECNOLOGIAS E A CARTOGRAFIA SOCIAL PARA A REPRESENTAÇÃO DE TERRITÓRIOS EM CONFLITOS AMBIENTAIS NO NORTE DO TOCANTINS
}

\section{GEOTECHNOLOGIES AND SOCIAL CARTOGRAPHY FOR THE REPRESENTATION OF TERRITORIES IN ENVIRONMENTAL CONFLICTS IN NORTHERN TOCANTINS}

Vinicius Gomes de Aguiar ${ }^{1}$

\begin{abstract}
RESUMO
Comunidades tradicionais que ocupam historicamente seus territórios, apropriam-se dos recursos naturais para a produção econômica, segurança alimentar e o desenvolvimento dos hábitos culturais. A diversidade de espaços, assim como as infinidades de formas para que ocorra a sua representação espacial, induziram a organização da cartografia social, que envolve a participação dos grupos locais e está relacionado com a troca dialética entre a comunidade e pesquisadores, como o que ocorreu na comunidade Ilha Verde, em Babaçulândia (TO). Sendo assim, o objetivo deste trabalho é discutir as diferentes possibilidades de se utilizar as geotecnologias nos trabalhos envolvendo a cartografia social em comunidades tradicionais.
\end{abstract}

PALAVRAS-CHAVE: cartografia; território; comunidades.

\begin{abstract}
Traditional communities that occupy their territories historically, appropriating the natural resources for economic production, food security and the development of cultural habits. The diversity of spaces, as well as the infinity of forms for their spatial representation to occur, induced the organization of social cartography, which involves the participation of local groups and is related to the dialectical exchange between the community and Researchers, such as what happened in the Green Island community in Babaçulândia (TO). Thus, the objective of this work is to discuss the different possibilities of using geotechnologies in the work involving social cartography in traditional communities.
\end{abstract}

KEYWORDS: cartography; territory; communities.

\footnotetext{
${ }^{1}$ Doutorado em Geografia pela Universidade Federal de Goiás (2015) e docente do curso de licenciatura em Geografia da Universidade Federal do Tocantins, é membro do Neuza - Núcleo de Pesquisa e Extensão em Saberes e Práticas Agroecológicas - e atua como professor colaborador do Programa de PósGraduação em Estudos de Cultura e Território (PPGCult).
} 


\section{INTRODUÇÃO}

Ao observar as marcas históricas e espaciais através do conceito de território, torna-se possível observar que ele integra, tanto a abordagem materialista - relacionado diretamente, mas não exclusivamente, com o espaço físico e a terra -, quanto a idealista ou simbólica - que se aproxima das questões imateriais e simbólicas. Assim, para entender o território é necessário organizar uma observação de forma a integrar as diferentes questões da relação sociedade-natureza (HAESBAERT, 2009).

$\mathrm{Na}$ ideia de território integrado, o controle e o ordenamento territorial, muitas vezes trabalhados nos planos diretores municipais, planos de manejo de unidades de conservação, entre outros projetos que envolvem questões espaciais e socioambientais, têm motivado debates, pois tem considerado o território como: um espaço de relações de poder, em busca do controle de acesso e fluxo, de pessoas e bens; eventualmente uma unidade espacial que propicia o entendimento relacionado ao território como rede, envolvendo integração e movimento; e em outro caso, entende o território como uma relação entre o material e o simbólico, conectando natureza e sociedade (HAESBAERT, 2009). Sendo assim, para se discutir a ideia de território integrado trabalharemos diferentes concepções, porém será utilizado mais diretamente o último entendimento descrito.

Ao observar o território de forma integrada, a territorialidade, item importante para a concepção de um território, insere-se no espaço como mediador das relações de poder que influencia e controla pessoas, recursos e/ou relações sociais. Pois nesse caso, a territorialidade é entendida como a busca pela influência ou controle de pessoas, fenômenos e relacionamentos, destinada a delimitar e controlar uma determinada área, entendida como território (SACHS, 1986).

Comunidades tradicionais que ocupam historicamente seus territórios, apropriamse dos recursos naturais para a produção econômica, segurança alimentar e o desenvolvimento dos hábitos culturais. Além desses grupos estarem inseridos em diversas relações de poder, seus territórios tornam-se um instrumento utilizado para a padronização e classificação em relação aos outros territórios. Já que, os inseridos em um território, de alguma forma, podem ser entendidos como iguais por estarem inseridos no mesmo modelo de controle interno, assim como pela diferença existente entre os inseridos no território e os não inseridos (HAESBAERT, 2009). 
Logo, as relações de poder mediadas pelo espaço também produzem identidade, uma vez que

controla, distingue, separa e, ao separar, de alguma forma nomeia e classifica os indivíduos e os grupos sociais. E vice-versa: todo processo de identificação social é também relação política, acionada como estratégia em momentos de conflito e/ou negociação (HAESBAERT, 2009, pág. 88).

Mesmo nos dias de hoje, momento em que a globalização econômica tornou os espaços mais fluidos, a cultura e a identidade proporcionam um reposicionamento de indivíduos no espaço onde eles se unem em busca da manutenção de suas especificidades sociais, espaciais e históricas. Dessa forma, a segregação social, que tende em muitos momentos a eliminar as relações com o território, pode desenvolver o efeito contrário, pois a dificuldade cotidiana de se manter, induz diversos grupos a se aproximarem ideologicamente e especialmente em busca da manutenção de sua identidade, como uma forma de busca pelo mínimo de dignidade (HAESBAERT, 2009).

Todo esse cenário pode ser percebido em inúmeros locais onde ocorrem conflitos ambientais e territoriais. Sendo que esta pesquisa entende conflito ambiental como uma importante categoria de análise espacial por possibilitar compreender as disputas baseados em objetivos e interesses conflitantes, de diferentes grupos sociais, relacionados à apropriação do território e dos recursos naturais existentes, onde estão envolvidos os agentes econômicos, populações e as instituições (PORTO, ROCHA e FINAMORE, 2014), tanto públicas, quanto privadas.

Sendo assim, o objetivo deste trabalho é compreender as diferentes possibilidades de se utilizar as geotecnologias nos trabalhos envolvendo a cartografia social em comunidades tradicionais, inseridas em conflitos ambientais e territoriais da região Norte do Estado do Tocantins.

\section{NORTE DO TOCANTINS}

O Estado do Tocantins surge em 1988, desmembrado do Estado de Goiás, após aproximadamente dois séculos de movimentos separatistas. Esse cenário proporcionou ao território tocantinense um novo dinamismo, que se estendeu igualmente à área norte do atual Estado (BELLIA et al., 2004).

Antes do norte goiano se tornar o Estado do Tocantins, esta região já havia recebido significativas intervenções. Dentre as mais importantes estão: 
a criação da comarca do Norte no final do século XVIII, a Marcha para o Oeste no governo de Getúlio Vargas nos anos 1930, o Plano de Metas executado por Juscelino Kubitschek na década de 1950 e os planos desenvolvimentistas elaborados no período ditatorial (RODRIGUES e OLIVEIRA, p. 42, 2013).

O território atual do Estado do Tocantins, durante o momento que pertencia a Goiás, recebeu tentativas de investidas em projetos públicos voltados para o adensamento populacional, a instalação de infraestrutura e incentivos para desenvolvimento de atividades produtivas, desde o século XVIII - com as atividades de mineração -, passando pelas políticas de ocupação do interior do país no início do século $\mathrm{XX}$ - muito marcada pela construção da rodovia BR-153 (Belém/Brasília) - (RODRIGUES e OLIVEIRA, 2013), até chegar nas últimas décadas com construção de diversos projetos hidrelétricos e o avanço do agronegócio saindo do Cerrado e indo em direção da Amazônia.

Este contexto induziu a disputa por territórios e recursos naturais envolvendo as comunidades tradicionais da região e os representantes dos projetos de desenvolvimento. Logo todo o Estado, especialmente a região norte do Tocantins, possui um histórico que induz a consolidação de práticas ambientalmente injustas e politicamente desproporcionais, apresentando significativas disputas nas últimas décadas quando as comunidades tradicionais, especialmente as rurais, tem passado por diversos problemas socioambientais.

Em 2017 o IBGE elaborou a divisão regional das Unidades da Federação organizando os estados em Divisão Geográfica Intermediária, que é subdividido em um conjunto de municípios que formam as Regiões Imediatas. No Tocantins existem 3 (três) regiões intermediárias - Palmas, Araguaína e Gurupi -, sendo que nesta pesquisa a região de Araguaína é considerada como o Norte do Tocantins, que por sua vez engloba espacialmente as regiões imediatas de Guaraí, Colinas do Tocantins, Araguaína, Tocantinópolis e Araguatins (Figura 01).

\section{COMUNIDADES TRADICIONAIS E JUSTIÇA AMBIENTAL}

Muitos pesquisadores entendem que as práticas produtivas das populações tradicionais propiciam pouca interferência na dinâmica do ambiente natural devido ao desenvolvimento de atividades exploratórias de baixo impacto. Diferente das degradações ambientais provenientes de grandes empreendimentos, especialmente os agroindustriais - muito comuns na região norte do Tocantins -, que tem expandido suas fronteiras nas últimas décadas em direção às comunidades que tradicionalmente ocupam seus 
territórios, promovendo um cenário de disputa ambiental e territorial, desproporcional e injusta. O que gera injustiça ambiental

o mecanismo pelo qual sociedades desiguais, do ponto de vista econômico e social, destinam a maior carga dos danos ambientais do desenvolvimento às populações de baixa renda, aos grupos raciais discriminados, aos povos étnicos tradicionais, aos bairros operários, às populações marginalizadas e vulneráveis (Rede Brasileira de Justiça Ambiental - RBJA -, 2001).

\section{MUNICÍPIOS E REGIÕES IMEDIATAS QUE COMPÕEM A REGIÃO GEOGRÁFICA INTERMEDIÁRIA DE ARAGUAÍNA - TO (2017)}

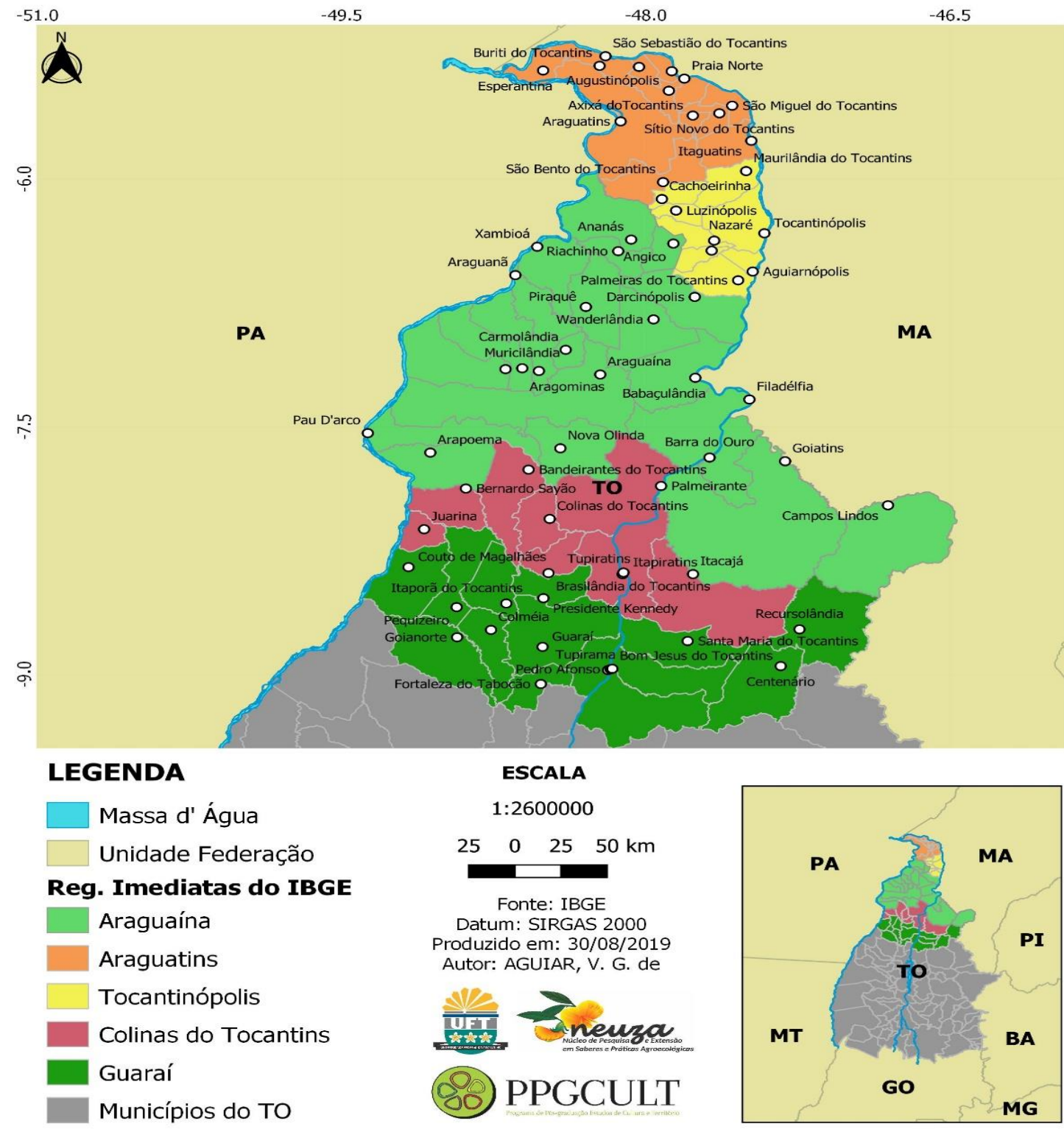

Figura 01. Municípios que compõem a região norte do Tocantins.

Condição diferente da desejada, ou seja, de justiça ambiental que é definida como o conjunto de ações que 
asseguram que nenhum grupo social, seja ele étnico, racial ou de classe, suporte uma parcela desproporcional das consequências ambientais negativas de operações econômicas, de decisões de políticas e de programas federais, estaduais, locais, assim como da ausência ou omissão de tais políticas

Inúmeros processos de injustiça ambiental têm sido mapeados pela Environmental Justice Organizations, Liabilities and Trade (EJOLT) - Organizações por Justiça, Passivos e Negociações Ambientais $-^{2}$, atividade essa coordenada pelo Joan MartinezAlier em conjunto com mais de 20 instituições pelo mundo, incluindo a FIOCRUZ como representante brasileira.

Neste projeto está inserido o Atlas da Justiça Ambiental, que é uma plataforma online de espacialização de dados referente a conflitos ambientais de todo planeta. A maioria dos casos representados no atlas são de comunidades contrárias aos impactos recebidos e que lutam por justiça ambiental. Dentre os conflitos representados pelo atlas, estão os provenientes de acidentes nucleares, extração mineral, gestão de resíduos, biomassa e os conflitos de uso das terras, os combustíveis fósseis e justiça climática, gestão de água, infraestrutura e o ambiente construído, turismo de lazer, conservação da biodiversidade, além de parques industriais e empresariais.

No Brasil, o Mapa dos Conflitos Ambientais - Figura 02 - gerido pela Rede Brasileira de Justiça Ambiental - RBJA -, além de catalogar os territórios onde ocorrem impactos (590 em todo o país) e riscos ambientais para as comunidades tidas como parte de uma minoria social, também reconhece estas populações como portadoras de direitos, dando publicidade às demandas locais por justiça (PORTO, PACHECO e LEROY, 2013). Este mapa é uma ferramenta de representação espacial dos impactos socioambientais e das injustiças ambientais, que fornece instrumentos para compor as exigências comunitárias e dos povos tradicionais para a busca da equidade, do acesso ininterrupto a terra e da participação efetiva por parte da população atingida em todas as etapas do licenciamento ambiental (LEROY e MEIRELES, 2013).

De acordo com Porto, Pacheco e Leroy (2013), para um caso ser inserido no Mapa de Conflitos do Brasil é preciso haver um conflito evidente, assim, eventualmente não ocorreu a inserção de situações de conflitos que reflitam situações de injustiça ambiental, independente da intensidade. Isso se deu por não existir uma reação da comunidade envolvida, ou de movimentos sociais e organizações solidárias. Logo, o Mapa de

\footnotetext{
${ }^{2}$ http://ejolt.org/
} 
Conflitos representa somente a "ponta do iceberg" dos problemas envolvendo os casos de injustiças ambientais no país (PORTO, PACHECO e LEROY, 2013).

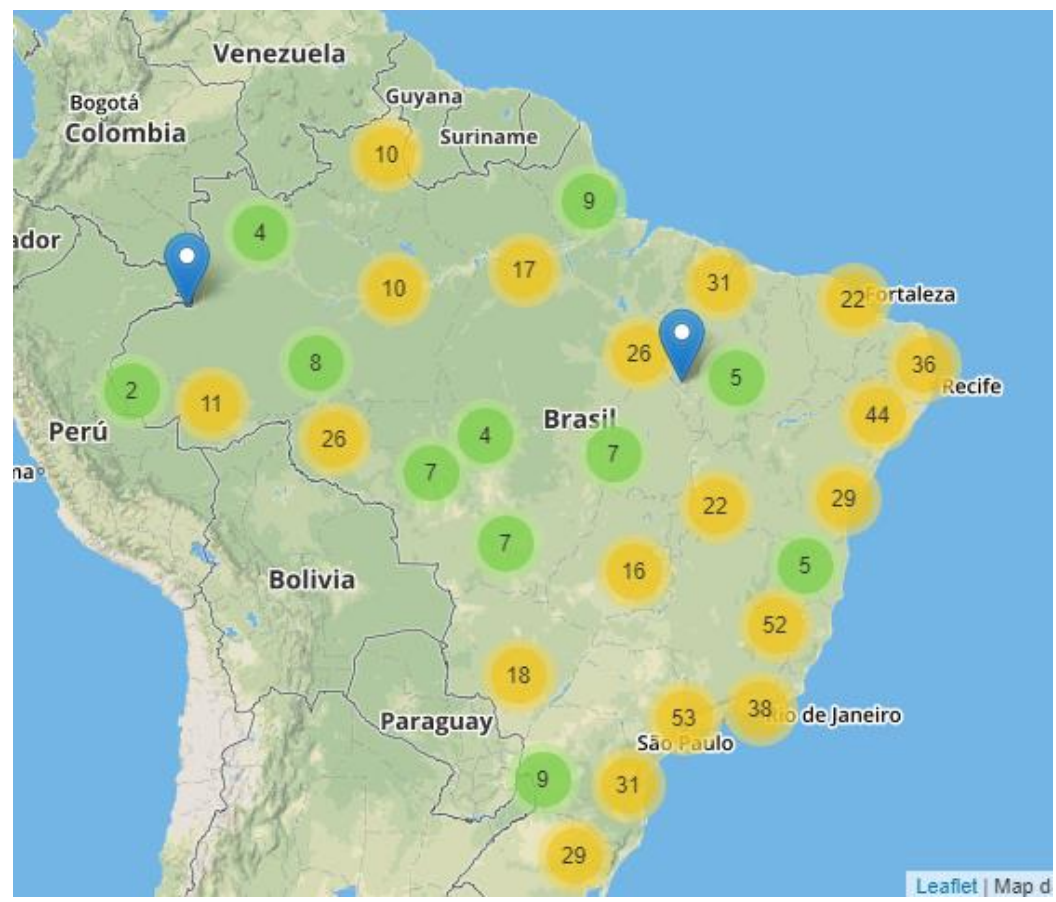

Figura 02. Mapa de conflitos envolvendo injustiça ambiental e Saúde no Brasil. Fonte: LIS/ICICT/Fiocruz. Disponível em: http://mapadeconflitos.ensp.fiocruz.br/.

Mesmo sendo considerado a "ponta do iceberg”, no Mapa de Conflitos o estado do Tocantins possui 16 (dezesseis) casos, sendo que se torna perceptível o maior número de conflitos na parte mais ao norte do estado (Figura 03). 


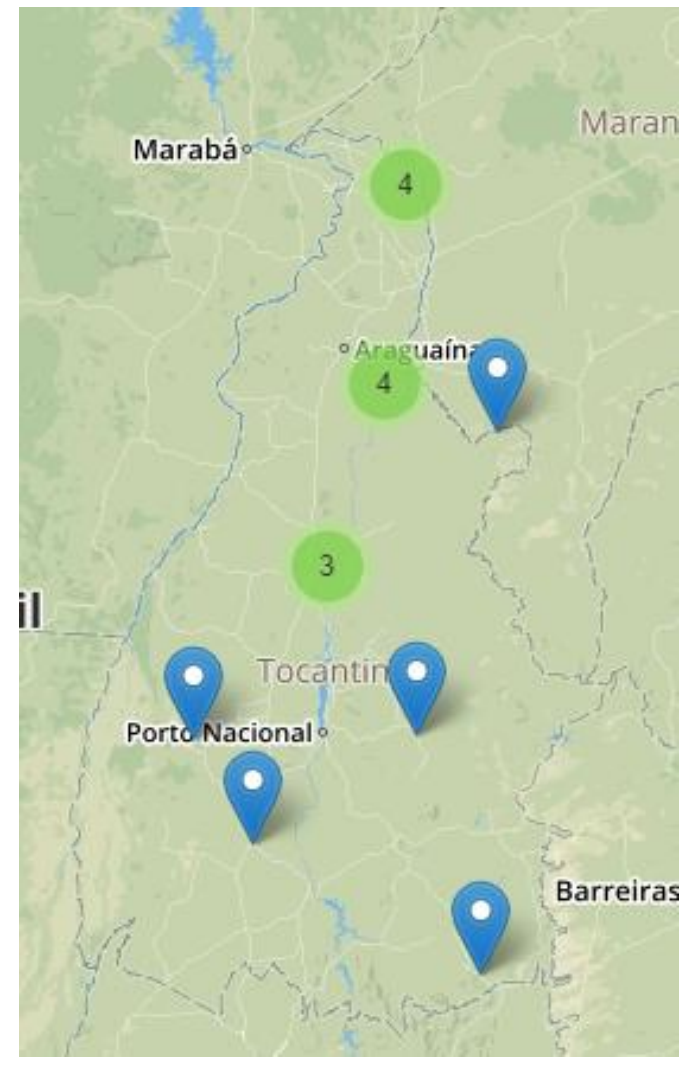

Figura 03. Casos de conflitos registrados no estado do Tocantins. Fonte: LIS/ICICT/Fiocruz. Disponível em: http://mapadeconflitos.ensp.fiocruz.br/.

Os casos existentes no Mapa de Conflitos não estão relacionados com solicitação de favores demandados por sobreviventes do passado, mas com comunidades que conseguiram manter sua subsistência, ou ainda buscam se garantir através da conservação da biodiversidade local e da soberania alimentar (LEROY e MEIRELES, 2013). Mesmo sabendo que diversos grupos sociais são impactados, as comunidades indígenas, quilombolas e outras tradicionais estão no caminho do desenvolvimento, ou seja, a identidade étnica ou a cor da população influencia na ocorrência de impactos ambientais sofridos (LEROY e MEIRELES, 2013).

No país, são nas áreas, urbanas ou rurais, ocupadas majoritariamente por populações negras, indígenas e outras populações tradicionais, que geralmente se instalam os empreendimentos que produzem um grande impacto socioambiental. Sendo ainda comum, no processo de realização de projetos voltados para o avanço da fronteira do capital, a desqualificação dos hábitos locais, especialmente de povos tradicionais, juntamente com a invisibilização dessas comunidades (PACHECO e FAUSTINO, 2013).

Naturalmente, não é possível afirmar que em todos os casos políticas ou ações empresariais atinjam uma determinada comunidade de forma intencional. Porém, tornase evidente que as dificuldades de acesso às instituições públicas, em conjunto com as 
ações políticas e econômicas desiguais, colocam as populações que tradicionalmente ocupam seus territórios em condições de fragilidade, tendo em vista o não acesso destas populações aos espaços de tomadas de decisões. Assim, o colonialismo no Brasil coloca as comunidades quilombolas, indígenas e outras populações tidas como tradicionais em situação de não equivalência nos processos de tomada de decisão, quase nunca estão envolvidos no sistema jurídico, muito pouco representados no poder legislativo e ainda tem seus saberes e necessidades inferiorizados devido à incompatibilidade com o modelo de progresso econômico. Sendo que o progresso e o desenvolvimento, neste caso, representam o agravamento da subordinação dos grupos não-brancos aos modelos socioeconômicos e políticos vigentes (PACHECO e FAUSTINO, 2013).

\section{CARTOGRAFIA SOCIAL EM TERRITÓRIOS TRADICIONAIS}

A diversidade de espaços, territórios, lugares, assim como as infinidades de formas para que ocorra a sua representação espacial, induziram a organização de um campo de atuação comumente conhecido no Brasil como cartografia social, mas também tem sido tratado como mapeamento participativo, mapeamento colaborativo, mapeamento comunitário etc. (ACSELRAD, 2008).

Porém, Acselrad (2008) percebe que ultimamente essa cartografia tem sido utilizada, tanto por iniciativas que auxiliam no processo de resistência das comunidades tradicionais e/ou etnicamente diferenciadas às pressões econômica, ambientais e territoriais proveniente de empreendimentos poluidores e indutores de desterritorialização, quanto como ferramenta que viabiliza a implementação desses empreendimentos por apresentar uma efetivação, apesar de ser apenas consultiva e burocrática, da participação das pessoas atingidas por essas atividades. A popularização dessa cartografia tem induzido a organização de diversas formas de interpretar o mundo, além de também acirrar as formas de monitoramento e controle socioambiental (ACSELRAD e COLI, 2008).

Como a cartografia tem buscado georreferenciar informações das mais diferentes perspectivas, muitas vezes passam a cartografar também conflitos envolvendo elementos pouco discutidos no cotidiano das sociedades, como por exemplo: as áreas de recursos naturais; áreas de relevante biodiversidade; territórios ocupados por grupos tradicionais; áreas urbanas ou rurais ocupadas majoritariamente por grupos raciais específicos; entre outros. 
Iniciativas de inclusão das comunidades tradicionais nas cartografias tem se popularizado mundialmente nas últimas 3 décadas, sendo realizada muitas vezes por meio de atuações de órgãos governamentais, ONG - organizações não governamentais -, associações étnicas (indígenas e quilombolas, especialmente) -, fundações privadas, universidades, algumas ações relacionadas ao licenciamento ambiental de empreendimentos que impactam os territórios e os ambientes dessas comunidades, etc.

Apesar das diferentes nomenclaturas aplicadas a este tipo de cartografia, internacionalmente existe um tratamento consolidado enquanto mapeamento participativo. De acordo com Herlihy e Knapp (2003), metodologias envolvendo a participação dos grupos locais estão relacionadas com a troca dialética entre representantes da comunidade e pesquisadores. Neste contexto, o mapeamento participativo, muito direcionado à representação das condições espaciais e ambientais, busca na comunidade as informações referentes a esses aspectos e o representa utilizando elementos da cartografia convencional. Dentre as ferramentas utilizadas para a representação cartográfica estão: os mapas tridimensionais feitos à mão, baseado nos contornos de mapas oficiais ampliados; e as geotecnologias utilizadas atualmente, como por exemplo as bases cartográficas digitais oficiais dos Estados, os sistemas de informação geográfica - SIG -, o sistema de posicionamento global - GPS - e o sensoriamento remoto, através do tratamento de imagens aéreas (ACSELRAD e COLI, 2008).

Neste contexto o SIG, ambiente computacional onde se processa e manipula os dados obtidos com o auxílio das geotecnologias, representa a ferramenta de integração das informações espaciais, tendo em vista que ao ser aplicado no tratamento computacional de dados geográficos, fornece uma visão da área observada. Para a visualização das informações espaciais os dados precisam estar georreferenciados, "isto é, localizados na superfície terrestre e representados numa projeção cartográfica" (CÂMARA e QUEIROZ, p. 3-1, 2004). Dentre as principais características dos SIGs estão: a inserção e integração, numa base de dados, de todas as informações espaciais; e oferecer mecanismos para combinar as diversas informações, consultar, recuperar, visualizar e plotar o conteúdo da base de dados georreferenciados (CÂMARA e QUEIROZ, 2004).

Assim a comunidade local, com o auxílio de um SIG, tem a possibilidade de mapear os elementos mais representativos para ela. Porém, especialmente nos primeiros momentos, torna necessário a efetivação de parcerias entre as comunidades e as 
universidades, ONGs e entidades públicas, que possua pessoal treinado voltado para a gestão dos dados espaciais e que também ofereça formação para a comunidade organizar seus próprios mapas, pois estes mapeamentos têm sido aplicados na demarcação de seus territórios, na espacialização de suas territorialidades e no manejo e zoneamento das suas áreas (ACSELRAD e COLI, 2008).

No norte do Tocantins algumas entidades tem se dedicado a atuar em conjunto com as comunidades locais, como a Alternativa para a Pequena Agricultura no Tocantins (APA-TO) que atua em conjunto com o grupo da Nova Cartografia Social da Amazônia (PNCSA) e a Universidade Federal do Tocantins (UFT) por meio do curso de Educação do Campo em Tocantinópolis e também do Núcleo de Pesquisa e Extensão em Práticas e Saberes Agroecológicos (NEUZA), em Araguaína.

Segundo Almeida (2013), no âmbito da cartografia social, o processo de formação inicial nas comunidades envolve aprendizados relacionados: a constituição federal; a legislação ambiental; assim como as técnicas de manipulação e gestão dos dados obtidos com receptores GPS em um SIG; tendo a consolidação realizada por meio de oficinas de mapas nas comunidades. Esses espaços de formação permitem, tanto à comunidade produzir a delimitação de áreas, quanto a demarcação de locais observados em campo ou descritos por representantes da comunidade no mapa, o que viabiliza a realização de diversos trabalhos, incluindo uma descrição etnográfica.

Um trabalho de cartografia social de destaque no Brasil é o Projeto Nova Cartografia Social da Amazônia (PNCSA) coordenado por Alfredo Wagner de Almeida. Este projeto tem analisado as diferentes formas de territorialização na Amazônia atualmente, expressas por uma significativa diversidade de identidades coletivas, como por exemplo:

\footnotetext{
ribeirinhos, seringueiros, quilombolas, indígenas, piaçabeiros, pescadores artesanais, castanheiros, artesãos e artesãs (do arumã, do tucum, do cipó ambé e das palhas e sementes), indígenas que residem em cidades, quebradeiras de coco babaçu e peconheiros (coletores de açaí) dentre outras (ALMEIDA, p. 28, 2013).
}

Em cada identidade ocorre um agrupamento de organização própria, que forma, no decorrer do tempo e das articulações, suas territorialidades específicas. Isso tem induzido uma crescente autoconsciência sociocultural nessas comunidades para a mobilização de forças, com o intuito conservar suas condições ambientais e territoriais em oposição aos interesses produtivos responsáveis por inúmeros processos geradores de degradação ambiental. Sendo assim, tem sido muito comum campanhas e ações de 
enfrentamento contra projetos de ampliação do agronegócio, atividade mineradora, implantação de empreendimentos turísticos e imobiliários, entre outros, tornando a cartografia social uma metodologia de mapeamento das mobilizações, oferecendo destaque aos aspectos considerados mais relevantes pela comunidade (ALMEIDA, p. 2013).

No município de Babaçulândia (TO), a comunidade rural Ilha Verde que está localizada às margens do lago da Usina Hidrelétrica (UHE) de Estreito, teve uma ação judicial que determinou a retirada dessa comunidade do território. Com a intenção de resistir no território, a comunidade em conjunto com a Defensoria Pública do Tocantins convidou o NEUZA-UFT para auxiliar na produção de um mapa que contextualizasse suas formas de ocupação (Figuras 04 e 05). Durante a atividade em campo, as pessoas inseridas no NEUZA-UFT em conjunto com outros pesquisadores (estudantes de graduação, pós-graduação e professores de outros campus da UFT), utilizaram receptores GPS (Global Position System) para identificar a posição das ocupações da comunidade em relação a Área de Preservação Permanente (APP) do lago da UHE Estreito (Figura 06).

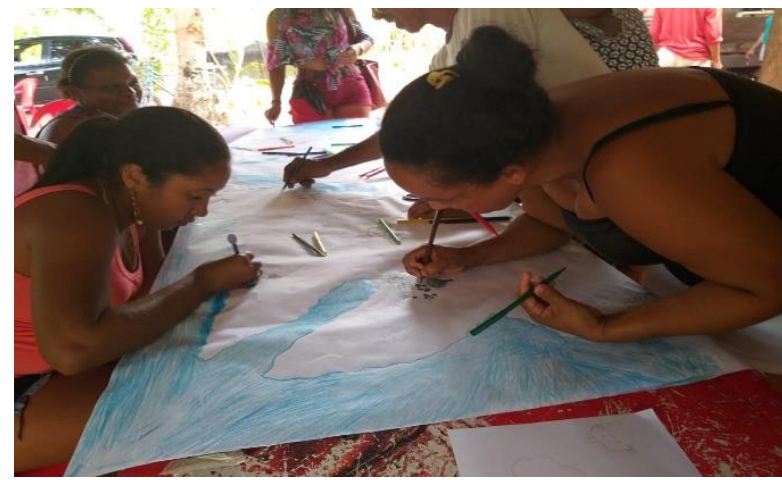

Figura 04. Mulheres da Ilha Verde realizando o desenho do mapa da comunidade.

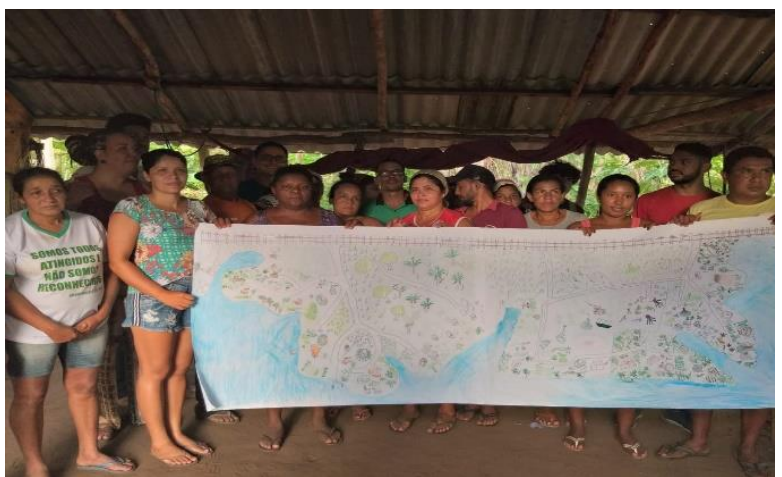

Figura 05. Mapa desenhado pela comunidade Ilha Verde. 


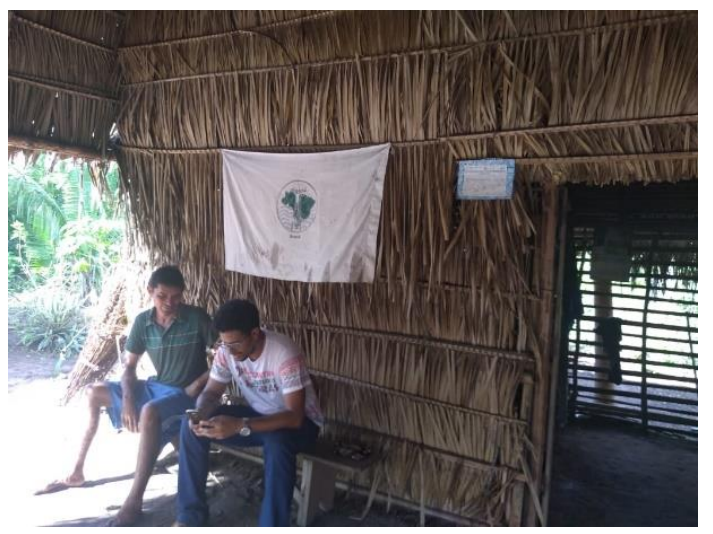

Figura 06. Pesquisador do Neuza coletando informações com GPS em conjunto com um membro da comunidade

Como um dos resultados da atividade, foi percebido que a comunidade possui residências (Figura 07), que estão implantadas em 31 pontos, mas somente 6 estão na APP, mesmo assim o processo judicial para a retirada da comunidade de suas terras ainda se se manteve, consolidando um processo ambientalmente injusto em uma comunidade

\section{Comunidade Ilha Verde: Localização das Residências em Relação a APP de 30m do Lago da UHE de Estreito}

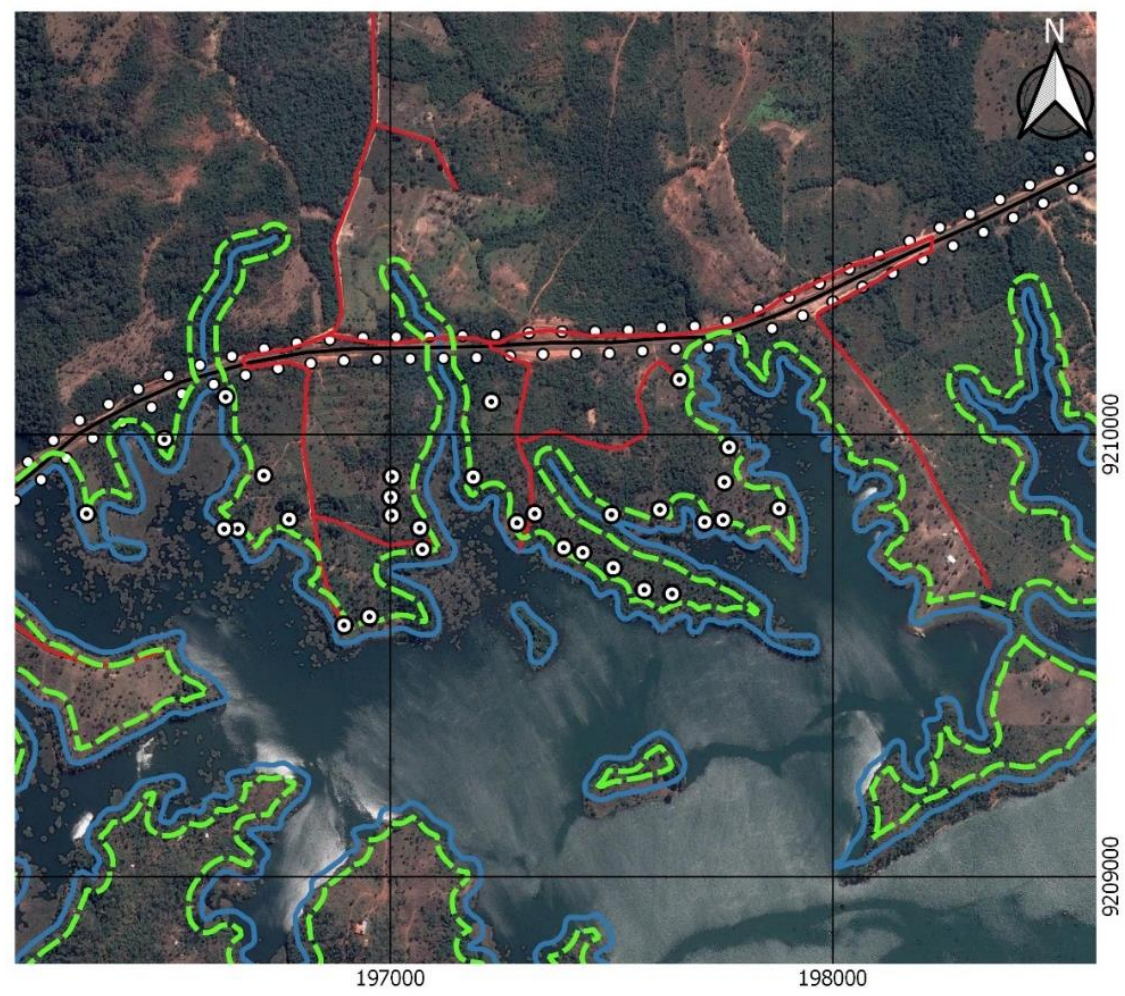

\section{Legenda}

$\odot$ Residências

[-. APP de $30 \mathrm{~m}$

- Trecho Rodoviario

o o Ferrovia

camponesa.

$\square$ Lago da UHE de Estreito

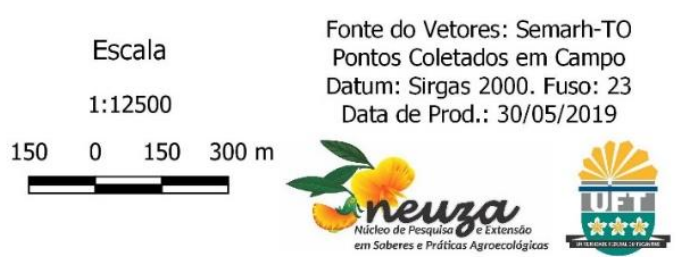


Figura 07. Localização das residências da comunidade Ilha Verde.

\section{Considerações Finais}

As atividades envolvendo cartografias sociais têm viabilizado, dentre outras coisas, a visibilização de resistências às dinâmicas econômicas globais, por fortalecer a autonomia na gestão de seus territórios. Esse processo tem auxiliado na resistência das comunidades aos efeitos dos empreendimentos impactantes (ACSELRAD, 2008).

A aproximação entre a universidade e as comunidades tradicionais, com o intuito de conhecer a dinâmica cultural e territorial desses grupos, como o caso que ocorreu na comunidade Ilha Verde, permite dimensionar o impacto de um empreendimento instalados nesses territórios.

Sendo assim, com a comunidade inserindo sua percepção ambiental, territorial e cultural em um mapa de seu território, qualquer projeto de alteração das condições representadas nessa cartografia social terá que ser pensada de modo a não degradar as condições ambientais locais e não inviabilizar a manutenção das práticas tradicionais dessa comunidade.

\section{Referências Bibliográficas}

ACSELRAD, Henri (org). Cartografias sociais e território. Rio de Janeiro. Universidade Federal do Rio de Janeiro, Instituto de Pesquisa e Planejamento Urbano e Regional, 2008.

ACSELRAD, Henri e COLI, Luis Régis. Disputas territoriais e disputas cartográficas. In: ACSELRAD, Henri (org). Cartografias sociais e território. Rio de Janeiro. Universidade Federal do Rio de Janeiro, Instituto de Pesquisa e Planejamento Urbano e Regional, 2008.

ALMEIDA, Alfredo Wagner Berno de. Nova Cartografia Social da Amazônia. In: ALMEIDA, Alfredo Wagner Berno de e FARIAS JÚNIOR, Emmanuel de Almeida (org.). Povos e comunidades tradicionais: nova cartografia social. Manaus. UFAM, 2013. Disponível em: http://novacartografiasocial.com.br. Acessado em: 05/07/2018.

BELLIA, Vitor et al. Plano de Zoneamento Ecológico-Econômico do Norte do Estado do Tocantins. Secretaria do Planejamento e Meio Ambiente (Seplan). Diretoria de Zoneamento Ecológico-Econômico (DZE). Projeto de Gestão Ambiental Integrada da Região do Bico do Papagaio. Palmas. Seplan/DZE, 2004. Disponível em: https://seplan.to.gov.br/. Acessado em: 09/07/2018. 
CAMARA, Gilberto e QUEIROZ, Gilberto Ribeiro de. Arquitetura de sistemas de informação geográfica. In.: CAMARA, Gilberto; MONTEIRO, Antônio Miguel; MEDEIROS, José Simeao de (Org.). Introdução à ciência da geoinformação. São José dos Campos. INPE, 2004.

HAESBAERT, Rogério. O mito da desterritorialização: do "fim dos territórios" à multiterritorialidade. 4ed. Rio de Janeiro. Bertrand Brasil, 2009.

HERLIHY, Peter H. e KNAPP, Gregory. Maps of, by, and for the Peoples of Latin America. Human Organization: Winter 2003, Vol. 62, No. 4, pp. 303-314. Disponível em: http://sfaajournals.net/doi/abs/10.17730/humo.62.4.8763apjq8u053p03. Acessado em: 07/07/2018.

LEROY, Jean Pierre e MEIRELES, Jeovah. Povos indígenas e comunidades tradicionais: os visados territórios dos invisíveis. In: Injustiça ambinetal e saúde no Brasil: o mapa de conflitos, por PORTO, Marcelo Firpo; PACHECO, Tânia e LEROY, Jean Pierre (Org.), 115 - 131. Rio de Janeiro, Ed. FIOCRUZ, 2013.

PACHECO, Tânia e FAUSTINO, Cristiane. A iniludível e desumana prevalência do racismo ambiental nos conflitos do mapa. In: Injustiça ambinetal e saúde no Brasil: o mapa de conflitos, por PORTO, Marcelo Firpo; PACHECO, Tânia e LEROY, Jean Pierre (Org.), 115 - 131. Rio de Janeiro, Ed. FIOCRUZ, 2013.

PORTO, Marcelo Firpo; PACHECO, Tânia e LEROY, Jean Pierre. Injustiça ambiental e saúde no Brasil: o mapa de conflitos. Rio de Janeiro, Ed. FIOCRUZ, 2013.

PORTO, Marcelo Firpo; ROCHA, Diogo Ferreira da; e FINAMORE, Renan Finamore. Saúde coletiva, território e conflitos ambientais: bases para um enfoque socioambiental crítico. Revista Ciência \& Saúde Coletiva, 19(10):4071-4080, 2014.

REDE BRASILEIRA DE JUSTIÇA AMBIENTAL - RBJA. Manifesto de lançamento da Rede Brasileira de Justiça Ambiental. Niterói, 2001. Disponível em: http://www.justicaambiental.org.br/. Acessado em: 02/09/2014.

RODRIGUES, Waldecy e OLIVEIRA, Thiago José Arruda de. O norte do Goiás antes do Tocantins: as decisões do estado que influenciaram no processo de criação desta nova unidade da federação. Fronteiras, Dourados, MS, v.15, n.26, p.57-71, 2013. Disponível em: http://ojs.ufgd.edu.br/index.php/FRONTEIRAS. Acessado em: 09/07/2018.

SACHS, Ignacy. Espaços, tempos e estratégias de desenvolvimento. São Paulo: Vértice, 1986. 